\title{
A CONSTRUÇÃO DA DIGNIDADE HUMANA POR MEIO DA EDUCAÇÃO E DO TRABALHO
}

\author{
THE DEVELOPMENT OF HUMAN DIGNITY \\ THROUGH EDUCATION AND LABOR
}

\author{
LUCIANA ZACHARIAS GOMES FERREIRA COELHO ${ }^{1}$
}

\begin{abstract}
RESUMO: A dignidade da pessoa humana é princípio constitucional fundamental do ordenamento jurídico brasileiro, consistindo em importante diretriz a nortear o Estado em todas suas esferas de atuação. Deveras, somente assegurando a cada indivíduo o mínimo existencial para uma vida digna, com atendimento das necessidades básicas para o bem-estar e desenvolvimento pessoal, material e espiritual, será possível a construção de uma sociedade verdadeiramente solidária, consoante os ditames da Carta Magna. Todavia, a ordem social contemporânea não contempla as exigências mínimas de satisfação humana, restando grande parte da população à margem de qualquer amparo material, moral e intelectual, impossibilitada de prover, por meio do trabalho, o sustento e a dignidade para si e para os seus. Em face de uma sociedade dominada pelos interesses do capital em todas as suas dimensões, os menos privilegiados buscam na educação formal a possibilidade de ascensão e auto-realização. Cabe ao Estado a tarefa de universalizar o trabalho e propiciar uma educação transformadora, calcada no saber crítico e humanístico, apta a questionar e até mesmo modificar os mecanismos de acumulação de capital do modo de produção vigente, ao qual a própria máquina estatal encontra-se subordinada. É urgente a tomada de medidas capazes de alterar este panorama, resgatando o espírito crítico da sociedade e buscando novas formas de consciência social, para que todos vivam - e não apenas sobrevivam - de forma digna.

PALAVRAS-CHAVE: Dignidade Humana; Educação; Trabalho.
\end{abstract}

ABSTRACT: The human dignity is an essential constitutional principle of the Brazilian legal system, consisting in an important guideline to the State in all its spheres of activity. Indeed, only ensuring that every individual has the existential minimum for a decent life with basic needs for the welfare and personal, material

\footnotetext{
Artigo recebido em 30.04.2012. Pareceres emitidos em 24.08.2012 e 02.09.2012.

Artigo aceito para publicação em 19.11.2012.

${ }^{1}$ Advogada e Docente Efetiva da Universidade Federal de Uberlândia (UFU), lotada na Faculdade de Ciências Integradas do Pontal (FACIP). Especialista em Direito Processual Civil pela UFU e Mestra em Direito Obrigacional Privado pela Universidade Estadual Paulista "Júlio de Mesquita Filho" (UNESP), câmpus de Franca. Doutoranda em Educação pelo Programa de Pós-Graduação em Educação da UFU, na linha de pesquisa Trabalho, Sociedade e Educação, sob orientação da Prof $^{\mathrm{a}}$ Dra $^{\mathrm{a}}$ Fabiane Santana Previtali. Iucianazachariascoelho@gmail.com
} 
and spiritual development, it will be possible to build a truly caring society, according to the dictates of the Constitution. However, the contemporary social order does not address the minimum requirements for human fulfillment, leaving a great part of the population without regard to any material, moral and intellectual support, unable to sustain, through their work, livelihood and dignity for themselves and their own. Living in a society dominated by the interests of capital in all its dimensions, the less privileged seek in formal education the possibility of ascension and self-realization. It is a task of the State to universalize work and provide a transformative education, based on humanistic and critical knowledge, with people able to question and even modify the mechanisms of capital accumulation of the existing mode of production, to which the state machinery is subordinated. It is urgent to take measures capable of changing this picture, recovering the critical spirit of society and seeking new forms of social consciousness, for all to live - and not just survive - in a dignified manner.

KEYWORDS: Human Dignity; Education; Labor.

SUMÁRIO: Introdução; 1. A Dignidade Humana enquanto Valor Constitucional; 2. Educação, Trabalho e Interesses do Capital; 3. A Construção da Dignidade Humana pela Educação e pelo Trabalho; Considerações Finais; Referências.

SUMMARY: Introduction; 1 . The Human Dignity as a Constitutional Value; 2. Education, Labor and Capital Interests; 3. The Construction of Human Dignity through Education and Labor; Final Remarks; References.

\section{INTRODUÇÃO}

A educação nos moldes atuais encontra-se voltada mormente para a priorização de interesses individualistas e competitivos, para formar supostamente - mão de obra qualificada para o mercado de trabalho, ao mesmo tempo em que produz cidadãos alijados de espírito crítico, incapazes de promover as necessárias mudanças para reverter o quadro de profunda desigualdade social que se estabeleceu no mundo contemporâneo.

O tema da mercantilização da educação vem sendo amplamente debatido, à luz das análises sobre a globalização, a reestruturação produtiva, as relações entre trabalho e capital e, sobretudo, em relação à crise estrutural enfrentada por este último. A desvalorização da força de trabalho, e respectiva valorização das mercadorias que reproduzem esta força, alteram a estrutura educacional e favorecem mais a aprendizagem e o ensino do saber técnico do que a educação em si, a qual deve estar voltada para formação do ser humano global, socializado e capaz de superar o individualismo.

Não se pode negar a importância do preparo do indivíduo para o trabalho, haja vista que é por meio dele que se obtêm os recursos necessários para prover a carne e o espírito, promovendo bem-estar material e desenvolvimento em condições de liberdade e dignidade. Por meio de seu lavor, o cidadão transforma a natureza, produz valores de uso, provê para si e para os seus, contribui para o desenvolvimento material da humanidade e o incremento das condições de vida do meio em que vive, realiza seu potencial físico e intelectual, buscando alcançar a tão almejada felicidade e reproduzir sua própria existência. Todavia, a condição pós-moderna vem precarizando cada 
vez mais as relações de trabalho, como se depreende das atuais práticas de flexibilização dos processos produtivos, seja em termos de intensificação da carga horária, terceirizações e contratações temporárias, múltiplas atribuições ao trabalhador, minimização de mão de obra e maximização da produção, metas de rendimento e produtividade, dentre outras mazelas que incutem no indivíduo o temor da perda de sua fonte de subsistência caso não se submeta às regras estabelecidas por um modo de produção capitalista perverso.

Esclarece Ponce (2007) que o trabalhador, no capitalismo, não colhe os frutos de seu trabalho. Se no início o trabalhador trocava o objeto que havia produzido do mesmo modo e que tinha valor equivalente, a partir do aparecimento de enormes massas de "trabalhadores livres" que ofereciam à venda sua força de trabalho, surgiram os alicerces de um novo regime, pelo qual o capitalista dá ao trabalhador muito menos do que o valor do objeto produzido, de modo que o salário a ele pago mal possibilita sua manutenção e retorno para vender ao capitalista, nas mesmas condições, a sua força de trabalho.

Do ponto de vista do capitalista, a potencialidade multilateral dos seres humanos na sociedade é a base sobre a qual se efetua a ampliação de seu capital. Ele, portanto, empreende todos os meios de aumentar a produção da força de trabalho que comprou quando a põe em ação. Os meios que ele utiliza podem variar desde o obrigar o trabalhador à jornada mais longa possível, como era comum nos inícios do capitalismo, até a utilização dos mais produtivos instrumentos de trabalho e a maior intensidade deste [...] porque é isso que lhe renderá o maior excedente e assim o maior lucro. (BRAVERMAN, 1987)

Sem alternativas, portanto, o indivíduo mergulha quase que integralmente no trabalho; não mais pela auto-realização que o mesmo deveria proporcionar, mas pelo receio de que, em não aderindo à lógica do capital, seja colocado à margem de uma sociedade calcada nas aparências, no individualismo e no consumo excessivo gerado pelas falsas necessidades internalizadas pelo sistema. Até mesmo o Estado, cujo papel deveria ser o de assegurar condições adequadas para o desenvolvimento pleno de todos os seus cidadãos, arrefece perante os ditames históricos, políticos, econômicos e sociais dos acumuladores do capital, reproduzindo seus interesses e relegando a segundo plano o bem-estar da população, ao privilegiar os resultados que a ideologia dominante demanda e degradar as condições de vida dos trabalhadores, na medida em que desregulamenta suas parcas conquistas nas relações de trabalho. O Estado é refém do capital financeiro globalizado e não pode investir na esfera social. As escolas estão mercantilizadas porque as políticas públicas se concentram em questões econômicas e, para buscar recursos, precisam apresentar volume de produtividade, comprovar índices de empregabilidade dos alunos, desenvolver novas tecnologias para o mercado, produzir mais em um tempo menor, etc. 
Infelizmente, nem todos os trabalhadores possuem a devida percepção dos mecanismos engendrados para propiciar a exploração de sua força de trabalho, muito menos estão cientes de seu potencial transformador da realidade. Isto porque a educação oferecida para a classe trabalhadora não vai além do mínimo necessário para capacitar o sujeito a exercer funções técnicas, afastando-o do saber filosófico, sociocultural, histórico, científico e crítico, o que só serviria para despertar insatisfações, dúvidas e questionamentos por parte daqueles que devem permanecer nos devidos lugares definidos pela classe dominante: trabalhadores desorganizados, disciplinados, conformados e inofensivos, que reproduzem ao máximo o capital por um mínimo de contrapartida.

Incapaz de absorver o grande contingente de trabalhadores sem colocação no mercado, seja por questões de qualificação do sujeito, mecanização da produção ou redução dos custos para maior lucratividade, o sistema capitalista vem, por meio do poder que exerce sobre o Estado, entabulando políticas voltadas para a formação de técnicos que possam atuar como prestadores de serviços, e também para a preparação de futuros "empreendedores", mascarando assim a questão do desemprego e do subemprego. Estes indivíduos, saindo dos bancos escolares, terão a árdua tarefa de sobreviver por conta própria, assumir riscos e gerar posições de trabalho para outros, arcando com os altíssimos custos do crédito ofertado pelas instituições financeiras e com a pesada carga tributária imposta pelo Estado.

A sociedade parece girar em um círculo vicioso, no qual a classe dominante deseja aumentar seus ganhos e lucros, valendo-se inclusive de mecanismos estatais para impor seus interesses - seja na política, economia ou educação -, tratando de explorar e alienar cada vez mais a classe trabalhadora, a qual, por sua vez, não vislumbra oportunidade para manter-se de outro modo que não seja submetendo-se ao sistema vigente, que a marginaliza e fragmenta, impedindo movimentos de luta capazes de instaurar um novo modo de produção que gere um círculo virtuoso de oportunidades equânimes.

\section{A DIGNIDADE HUMANA ENQUANTO VALOR CONSTITUCIONAL}

A dignidade humana apresenta-se como um conjunto de atributos inerentes à pessoa humana, possuindo conteúdo axiológico, haja vista a representação de valores que extrapolam a esfera do indivíduo, repercutindo em toda a esfera da coletividade. Este princípio encontra-se inserido no Estado Democrático de Direito, constituindo um dos principais fundamentos do sistema constitucional pátrio, com o escopo de assegurar o exercício dos direitos sociais e individuais, tais como a liberdade, a igualdade, a segurança, e o acesso à justiça, enquanto valores máximos de uma sociedade fraterna, pluralista e sem preconceitos, fundada na harmonia social e comprometida, na ordem interna e internacional, com a solução pacífica das controvérsias, como se depreende da análise do preâmbulo da Constituição Federal brasileira.

Pode-se afirmar que a dignidade humana é valor moral, espiritual e também material, na medida em que um mínimo indispensável de proteção 
aos valores extrapatrimoniais e patrimoniais devem ser assegurados pelo Estado e pela sociedade a cada indivíduo. Todo ser humano possui direito à autodeterminação e à liberdade na condução da própria vida, merecendo amplo amparo legal como medida de reconhecimento da própria essência e da condição de ser humano. Ressalte-se, no entanto, a existência de uma grande massa de pessoas socialmente excluídas e que sofrem da falta efetiva de um verdadeiro Estado Democrático de Direito, não obtendo sequer o mínimo de condições materiais para que possam gozar de uma vida digna e plena.

Os direitos e garantias fundamentais devem ser compreendidos não como fruto das estruturas estatais, mas como expressão suprema da vontade de todos os que compõem o corpo social. Compete ao Estado promover a dignidade da pessoa humana por meio de condutas ativas, garantindo o mínimo existencial para cada indivíduo. Tal dignidade é ofendida não apenas quando este indivíduo se vê despido das liberdades fundamentais, mas principalmente quando não possui acesso à alimentação, moradia, educação, saúde, trabalho, dentre outros.

A dignidade da pessoa humana encontra-se no bojo do ordenamento jurídico brasileiro, concebendo a valorização da pessoa humana como razão teleológica para a estrutura de organização do Estado e do Direito. O legislador constituinte elevou a dignidade da pessoa humana à categoria de princípio fundamental da República, um dos pilares essenciais da organização estatal, consoante artigo $1^{\circ}$, inciso III da Carta Magna de 1988.

Esclarece SARLET (2007):

[...] temos por dignidade da pessoa humana a qualidade intrínseca e distintiva de cada ser humano que o faz merecedor do mesmo respeito e consideração por parte do Estado e da comunidade, implicando, neste sentido, um complexo de direitos e deveres fundamentais que asseguram a pessoa tanto contra todo e qualquer ato de cunho degradante e desumano, como venham a lhe garantir as condições existenciais mínimas para uma vida saudável, além de propiciar e promover sua participação ativa e co-responsável nos destinos da própria existência e da vida em comunhão com os demais seres humanos.

A questão do mínimo existencial é complexa, deflagrando indagações sobre sua conceituação, a identificação das prestações consideradas indispensáveis para a manutenção de uma vida digna, o papel do Estado na promoção e proteção deste mínimo existencial, dentre outros questionamentos. Essa discussão tem como ponto de partida o papel do ordenamento em face da escassez de recursos e da possibilidade de se garantir determinados direitos para alguns em detrimento à satisfação de outros direitos para os demais. O desafio de efetivação do princípio da dignidade da pessoa humana é deveras árduo, mas sem dúvida perpassa pelo reconhecimento de que educação e trabalho figuram como um dos principais componentes na busca por sua implementação. 
A democracia somente se concretiza com a participação ativa do maior número de cidadãos, cuja inclusão neste cenário está estritamente vinculada ao acesso à educação. O Estado não logrará êxito em sua evolução apenas concentrando-se em prestações estatais voltadas para a subsistência de seus cidadãos. A construção da cidadania, também um fundamento do Estado brasileiro, deve estar alicerçada na concessão de instrução, no fomento ao ensino e na disseminação do conhecimento reflexivo.

O trabalho é também peça fundamental na construção da dignidade do homem, contribuindo para o seu aperfeiçoamento pessoal e material, bem como favorecendo o fortalecimento das relações sociais. Encontra-se, em última instância, direcionado para o bem-estar do ser humano, com o respaldo moral de poder assegurar a si e aos seus o sustento, a saúde, o lazer e o progresso contínuo. Os meios e as forças de produção social só se justificam se forem respeitados os valores humanos, mormente os que atinem à educação e ao trabalho, destinando-se ao bem estar e ao progresso coletivo. Vale ressaltar que todos são merecedores de desfrutar dos benefícios da produção da riqueza na medida em que dela são geradores.

O trabalho humano, especialmente o físico em relação ao intelectual, é pouco valorizado. Nota-se no modo de produção capitalista que quanto menor a remuneração, maior a oferta de mão de obra, uma vez que a qualificação exigida também é proporcionalmente menor. Assim sendo, pode-se dizer que a classe operária cujo nível educacional é inferior, encontra-se alijada dos processos decisórios de relevo e das oportunidades de maior ascensão social.

\section{EDUCAÇÃO, TRABALHO E INTERESSES DO CAPITAL}

Preconiza o artigo 205 da Constituição Federal de 1988 que "a educação, direito de todos e dever do Estado e da família, será promovida e incentivada com a colaboração da sociedade, visando ao pleno desenvolvimento da pessoa, seu preparo para o exercício da cidadania e sua qualificação para o trabalho". E, ainda, determina no inciso VII do artigo 206 a "garantia de padrão de qualidade" como princípio a embasar o ensino a ser ministrado.

A Lei de Diretrizes e Bases da Educação Nacional (LDB, Lei 9.394/96) busca atender, em seu bojo, ao comando legislativo constitucional, traçando normas para viabilização do ensino em todos os níveis - fundamental, médio e superior -, com especial ênfase na necessidade de tratamento do aluno não como simples receptor de conhecimentos, mas como indivíduo capaz de pensar criticamente o mundo ao seu redor, buscando a transformação e melhoria de si mesmo, assim como da sociedade na qual se insere. Faz-se necessário, pois, estabelecer diretrizes capazes de assegurar a qualidade do ensino em todas as suas dimensões.

Se o ensino fundamental e o médio devem cuidar da formação básica do cidadão, pois educação e cidadania devem andar de mãos dadas, 
o ensino superior tem de oferecer as ferramentas com as quais o indivíduo exercerá seu papel. A vida na sociedade atual exige um cidadão cada vez mais competente e informado, capaz de expressar sua opinião a respeito dos mais variados assuntos. Para tanto, qualquer cidadão deverá desenvolver as competências e habilidades básicas imprescindíveis à sua inserção na sociedade e no mercado de trabalho. Isso requer um nível de escolarização maior e de melhor qualidade, que lhe permita não apenas dominar o conhecimento, mas igualmente manejá-lo na solução de problemas. (NASCIMENTO, 2000)

Historicamente, a ideia de uma escola pública, universal, gratuita, obrigatória e laica remonta aos ideais liberais burgueses do século XVIII, que perceberam na educação escolar um recurso essencial para a consolidação da república sobre a monarquia, bem como a liberação dos ditames da Igreja Católica feudal, a qual monopolizava a função educacional para além da família. Na lição de Alves (2007), a escola universalizada ganhou novas dimensões no discurso de Horace Mann, educador norte-americano que preconizava que somente a distribuição equitativa da educação seria capaz de contrabalançar a tendência de domínio do capital e servilismo do trabalho. Em seu entendimento, se uma classe possuísse toda a riqueza e educação, enquanto o resto da sociedade permanecesse ignorante e pobre, esta última seria sempre servil e dependente da primeira, obtemperando que não havia homens inteligentes e práticos que permanecessem eternamente pobres.

Contudo, o crescimento da sociedade capitalista acabou por agravar diferenças sociais, e uma escola dualista passou a oferecer educação profissionalizante para os filhos dos trabalhadores e educação humanísticocientífica para os filhos dos dirigentes da sociedade. Para a superação da "escola tradicional", surge a proposta da escola única.

O princípio da unicidade postulava a necessidade de ser produzida uma instituição escolar única cujo currículo deveria integrar, harmonicamente, a educação profissional e a formação humanístico-científica [...]. O século XIX, portanto, além de projetar as possíveis conquistas da escola pública para o futuro, segundo uma matriz ideológica produzida originalmente por Horace Mann, acrescentou aos princípios revolucionários setecentistas, que resumiam o ideário da unicidade escolanovista [...]. Só a partir da década de 70 do século XIX, as nações assumiram políticas educacionais que, de forma consistente, alargaram a oferta da escola pública para todos. Mesmo nos países mais avançados, contudo, a universalização da escola só pode ser celebrada como uma conquista do século $X X$. (ALVES, 2007)

Chauí (1984) afirma que "faz parte da ideologia burguesa afirmar que a educação é um direito de todos os homens", demonstrando a autora, porém, a contradição entre os que produzem riqueza material e cultural com seu trabalho e aqueles que usufruem dessas riquezas, afastando delas os produtores. 
Estes últimos encontram-se excluídos do direito de usufruir dos bens que produzem, como por exemplo, o direito à educação. llustra o fato relembrando a situação do pedreiro que constrói a escola e do marceneiro que faz as carteiras, mesas e lousas - analfabetos que são, não possuem a menor condição de enviar seus filhos para a escola que foi por eles edificada.

Para Mészáros (2008), há uma profunda ligação entre os atuais processos educacionais e os processos sociais de reprodução, posto que aqueles se encontram em conformidade às exigências inalteráveis da lógica global do sistema reprodutivo. Assevera que não há possibilidade de legitimar o conflito entre forças hegemônicas fundamentais rivais em uma dada ordem social, pois não se pode cogitar uma formulação educacional que permita que a classe servil sobreponha-se à classe dominante. Assim sendo, o sistema vigente perpetua o domínio do capital como modo de reprodução social, mantendo os interesses objetivos da classe dominante.

A educação institucionalizada, especialmente nos últimos 150 anos, serviu - no seu todo - ao propósito de não só fornecer os conhecimentos e o pessoal necessário à máquina produtiva em expansão do sistema do capital, como também gerar e transmitir um quadro de valores que legitima (g.a) os interesses dominantes, como se não pudesse haver nenhuma alternativa à gestão da sociedade, seja na forma 'internalizada' (isto é, pelos indivíduos devidamente 'educados' e aceitos) ou através de uma dominação estrutural e uma subordinação hierárquica e implacavelmente imposta. (MÉSZÁROS, 2008)

No intuito de impor seus valores, a classe dominante se vale da "internalização", incutindo nos indivíduos a legitimidade de sua posição social, as expectativas adequadas, as condutas corretas; induz a uma aceitação ativa dos princípios reprodutivos orientadores preponderantes na sociedade de acordo com a posição de cada um e das tarefas que lhe são atribuídas, mantendo o proletariado em seu devido lugar. Esclarece o autor que o que carece de alteração não é apenas a instituição escolar em si, mas este próprio sistema de internalização, em todas as suas dimensões. A "contrainternalização" significaria não a negação do sistema atual, e sim o engendramento de uma alternativa abrangente ao que está posto, uma modificação estrutural da educação.

Hodiernamente, o educador e as disciplinas de cunho humanístico, que procuram desenvolver a consciência e o senso crítico, vêm perdendo a importância nas salas de aula. Não se desenvolve o "ser", mas o "ter" e o "saber fazer". Estimula-se a competitividade entre os colegas, o individualismo exacerbado, a capacitação para o trabalho técnico, criando formas mais profundas de internalizar os paradigmas de reprodução do capital.

Em meio ao movimento de extensão do capital aos complexos sociais em geral, o político, a educação e as políticas educacionais mercantilizam-se, 
produzindo relações sociais que se materializam em práticas humanas constituintes do sujeito - orientadas pela racionalidade do capital. [...]; estamos produzindo uma sociedade mercadorizada de forma totalizante; a esfera educacional tornou-se um quase-mercado (g.a.), a escola assemelha-se a um empório e o individualismo possessivo articulado à competitividade tornam-se os valores máximos de nossa educação subordinada ao mercado. Uma sociedade cujo ser social é um cidadão produtivo: útil, só e mudo. (SILVA JR., 2007)

\section{A CONSTRUÇÃO DA DIGNIDADE HUMANA PELA EDUCAÇÃO E PELO TRABALHO}

O Estado, regido e dominado pela classe burguesa ao longo da história, vem reproduzindo seus interesses e ideais, o que se reflete nas políticas que elabora e nas prioridades que elege quando de sua atuação.

A democracia burguesa sobrevive apenas com o consentimento da maioria dos governados; no entanto, ao mesmo tempo, tem que expressar o interesse distintivo da classe dirigente. Essa contradição se resolve apenas se o Estado se envolve ativamente na obtenção do consentimento das classes subordinadas. A ideologia proporciona um canal importante, e o poder estatal é, consequentemente, utilizado para influenciar a educação e para controlar, direta ou indiretamente, o fluxo de idéias e informações. [...] Essencialmente, o Estado talvez internalize em si mecanismos políticos que reflitam a luta de classes entre capital e trabalho. Assim, uma função chave inclui organizar e transferir determinados benefícios e garantias aos trabalhadores (padrões mínimos de vida e condições de trabalho, por exemplo), que talvez, para ser exato, não sejam do interesse econômico imediato da classe capitalista. Em troca, o Estado recebe a obediência genérica das classes subordinadas. (HARVEY, 2005)

Nos campos da educação e do trabalho, os desdobramentos desta subordinação impedem a auto-realização do indivíduo e a concretização do princípio da dignidade da pessoa humana, posto que os trabalhadores não recebem a devida instrução para compreender e libertar-se dos mecanismos de exploração do capital, sendo condenados à imobilidade social e à impossibilidade de realizar plenamente uma existência digna por meio de condições de trabalho justas.

A Constituição Federal brasileira elenca a educação e o trabalho no rol dos direitos sociais em seu artigo $6^{\circ}$, e estabelece no caput do artigo 170 que "a ordem econômica, fundada na valorização do trabalho humano e na livre iniciativa, tem por fim assegurar a todos existência digna, conforme os ditames da justiça social". Na mesma esteira, preconiza no artigo 205 que a educação é direito de todos e dever do Estado e da família, e que será promovida e incentivada com a colaboração da sociedade, visando ao desenvolvimento pleno da pessoa, seu preparo para o exercício da cidadania, bem como sua qualificação para o trabalho. Deveras, o fim do Estado é 
assegurar o bem comum, devendo para isso valer-se de todos os mecanismos para garantir à população as condições mínimas para alcançar uma verdadeira qualidade de vida.

No entendimento de Montoro (1999), a essência do bem comum repousa na vida dignamente humana da população, realizando-se quando o povo pode desenvolver normalmente suas faculdades naturais e virtudes humanas, como a amizade, a cultura, a vida familiar, dentre outras. O instrumento do bem comum são os bens materiais, o mínimo necessário para a realização de uma vida humana digna, como alimentos, habitação, vestuário e transportes; sua condição é a paz, o mínimo de unidade, tranquilidade e segurança sem o qual a sociedade não pode existir.

Referindo-se à doutrina de São Tomás de Aquino, esclarece que "conforme o pensamento tomista, uma sociedade só realiza o bem comum quando assegura à sua população não apenas a suficiência dos bens materiais, mas também aquele mínimo de liberdade e condições culturais para o exercício de uma vida humana digna" (MONTORO, 1999).

Embora estes preceitos encontrem-se sedimentados na legislação brasileira, sua efetivação prática certamente depende de fatores múltiplos, tais como a elaboração de políticas públicas voltadas para a alteração dos paradigmas educacionais e trabalhistas já estabelecidos; da luta social pela viabilização dos direitos dos cidadãos em todas as suas esferas; da conscientização da população acerca das reais condições de educação e trabalho às quais se encontram submetidas; do estabelecimento de novas ideologias e formulação de propostas capazes de promover alterações significativas do modo de produção atualmente em vigor.

Para França (2008), o valor da pessoa humana possui caráter universal e está vinculado à cidadania, cuja noção legitima a ação do Estado na busca da viabilização dos direitos fundamentais do cidadão. Contudo, a construção do Estado mínimo assume caráter político-ideológico, consistindo a educação em elemento chave do processo, restando a modernização do país centrada principalmente na educação profissional e instrumentalizada - sendo assim, educação e trabalho tornam-se os meios propícios para transmissão de princípios e valores doutrinários inerentes ao neoliberalismo.

Segundo Saes (2001), as ações estatais neoliberais estão evidenciadas no desmonte de políticas de incentivo à independência nacional, de promoção do bem-estar social, de instauração do pleno emprego e mediação dos conflitos socioeconômicos; abrangem, ainda, a privatização de atividades estatais, redução da atividade reguladora do Estado na economia e nas relações de trabalho, e também políticas de abertura da economia ao capital internacional, eliminando reservas de mercado e protecionismos.

Em meio a tantos acontecimentos, a classe trabalhadora fica à mercê dos efeitos negativos da globalização, como a desigualdade na produção e distribuição de bens e serviços, a expansão desenfreada dos processos 
econômicos, a massificação do consumo, dentre outros percalços que acabam por afetar a vida diuturna do cidadão comum.

Obtempera Mészáros (2008) que a educação formal, por si só, não é capaz de emancipar radicalmente a sociedade mercantilizada, mas exerce importante papel na elaboração de estratégias apropriadas e adequadas para mudar as condições objetivas de reprodução, promover a automudança consciente dos indivíduos chamados a concretizar uma ordem social diferente e garantir condições elementares da sobrevivência humana. É preciso, em sua opinião, universalizar a educação e o trabalho - principais canais de aprendizagem do indivíduo - para haver produtividade e igualdade material, alterando assim a relação de subordinação e dominação estrutural.

Hoje, sob o pretexto de que é preciso formar os estudantes para obter um lugar num mercado de trabalho afunilado, o saber prático tende a ocupar todo o espaço da escola, enquanto o saber filosófico é considerado como residual ou mesmo desnecessário, uma prática que, a médio prazo, ameaça a democracia, a República, a cidadania e a individualidade. Corremos o risco de ver o ensino reduzido a um simples processo de treinamento, a uma instrumentalização das pessoas, a um aprendizado que se exaure precocemente ao sabor das mudanças rápidas e brutais das formas técnicas e organizacionais do trabalho exigidas por uma implacável competitividade.

Daí, a difusão acelerada de propostas que levam a uma profissionalização precoce, à fragmentação da formação e à educação oferecida segundo diferentes níveis de qualidade, situação em que a privatização do processo educativo pode constituir um modelo ideal para assegurar a anulação das conquistas sociais dos últimos séculos. A escola deixará de ser o lugar de formação de verdadeiros cidadãos e tornar-se-á um celeiro de deficientes cívicos. (SANTOS, 2012)

\section{CONSIDERAÇÕES FINAIS}

Se por um lado a classe dominante só consegue visualizar a necessidade de expansão do capital a todo custo, sem perceber que o modo de produção por ela implementado contém em si o germe do próprio colapso, mediante o esgotamento desmedido de recursos materiais e humanos, por outro norte a classe trabalhadora assimila que a sociedade global, mercantilizada em todas as suas dimensões, consiste em intransponível limitação para qualquer estrutura alternativa. O Estado, cuja função social deveria ser a de mediador destes conflitos e desencadeador das possíveis mudanças, permanece envolvido com os interesses hegemônicos e pouco faz para reverter o quadro por meio de políticas emancipadoras voltadas para o resgate da dignidade na educação e no trabalho, além de outras esferas.

À míngua de atuação do poder público, a sociedade civil vem adotando interessantes mecanismos de protesto globalizados, valendo-se das redes sociais, da mídia e da comunicação eletrônica para despertar movimentos de 
resistência contra o domínio do capital e mobilizar a população. Por meio de grupos de discussão virtuais, questionam o modo de produção capitalista, demandam melhoria da qualidade de vida junto aos governantes, ocupam centros políticos e econômicos estratégicos, e até mesmo derrubam governos que tiranizam a população, como se depreende das notícias veiculadas pelo mundo.

Estes mecanismos parecem colaborar para a formação de um capital social, o qual, segundo Matos (2009), consistiria em um produto de um tipo particular de conversação cívica. Para a autora, somente uma comunicação comprometida com o interesse coletivo em sua origem, tendo como meta o benefício público, produz o capital social, o qual não se situa nem nos indivíduos ou nos meios de produção, mas nas redes sociais, que facilitam a coordenação e a cooperação, visando a um proveito mútuo. Referindo-se a estudos de Putnam, a autora esclarece que os indivíduos possuem maior possibilidade de mudar suas vidas quando fazem parte de uma comunidade cívica fortemente engajada, com influência sobre as esferas pública e privada. As redes de interação alargariam a consciência de seus membros, reforçando o gosto dos indivíduos pelos benefícios coletivos.

De todo modo, seja por meio da renovação do conteúdo da educação formal, da valorização das relações de trabalho, da reestruturação produtiva do capital ou da multiplicação das interações sociais conscientes, é preciso ter como norte a busca pela efetivação da dignidade humana. Faz-se necessário deflagrar um processo de construção normativa contextualizado aos tempos hodiernos, de racionalização do processo político e de legitimação de uma verdadeira consciência democrática, onde a responsabilidade pela quebra de paradigmas seja compartilhada por diversos atores sociais, no intuito de assegurar a existência plena das gerações futuras.

\section{REFERÊNCIAS}

ALVES, G. L. O Liberalismo e a Produção da Escola Pública Moderna. In LOMBARDI, J. C.; SANFELICE, J. L. (Orgs.). Liberalismo e Educação em Debate. Campinas, SP: Autores Associados, Histedbr, 2007.

BRAVERMAN, H. Trabalho e Capital Monopolista: a degradação do trabalho no Século XX. 3. ed., Rio de Janeiro: Zahar Editores, 1987.

CHAUÍ, M. S. O que é Ideologia. São Paulo: Abril Cultural/Editora Brasiliense, 1984.

FRANÇA, R. L. de. O Trabalho como Princípio da Dignidade da Pessoa Humana. In LUCENA, C. (Org.). Capitalismo, Estado e Educação. Campinas: Editora Alínea, 2008.

HARVEY, D. A Produção Capitalista do Espaço. São Paulo: Annablume, 2005.

MATOS, H. Capital Social e Comunicação: interfaces e articulações. São Paulo: Summus Editorial, 2009.

MÉSZÁROS, I. A Educação para Além do Capital. Trad. Isa Tavares. 2. ed., São Paulo: Boitempo, 2008.

MONTORO, A. F. Introdução à Ciência do Direito. 25. ed., São Paulo: Revista dos Tribunais, 1999. 
NASCIMENTO, E. M. F. S. et al. LDB, Ensino Superior e Construção da Cidadania. São Paulo: Editora Plêiade, 2000.

PONCE, A. Educação e Luta de Classes. Trad. José Severo de Camargo Pereira. 22. ed., São Paulo: Cortez, 2007.

SAES, D. República do Capital. São Paulo: Boitempo, 2001.

SANTOS, M. Os Deficientes Cívicos. Disponível em:

<http://www1.folha.uol.com.br/fol/brasil500/dc_3_9.htm>. Acesso em: 15 jan. 2012.

SARLET, I. W. Dignidade da Pessoa Humana e Direitos Fundamentais na Constituição Federal de 1988. 5. ed., Porto Alegre: Livraria do Advogado, 2007.

SILVA JR., J. R. O Longo Período do Esgarçamento do Pacto Social Liberal. In LOMBARDI, J. C.; SANFELICE, J. L. (Orgs.). Liberalismo e Educação em Debate. Campinas, SP: Autores Associados, Histedbr, 2007.

VADE MECUM. 11. ed., atual. ampl. São Paulo: Saraiva, 2011. 